\title{
Muss jede Pneumonie ins Krankenhaus?
}

\author{
Im höheren Alter erhöht sich das Risiko für eine ambulant erworbene Pneumonie (CAP). \\ Oft steht der Arzt dann vor der Frage, ob eine stationäre Einweisung wirklich nötig ist. \\ Der Geriater Prof. H. J. Heppner gibt Tipps für die individuelle Entscheidungsfindung.
}

? Beim Hausbesuch ergibt sich bei einem 78-jährigen Patienten der dringende Verdacht auf eine Lungenentzündung. Die 75-jährige Ehefrau ist sichtlich besorgt. Bei der Untersuchung erscheint der Patient stabil und ich sehe keinen zwingenden Grund für eine stationäre Behandlung. Ist das vertretbar?

Die ambulant erworbene Pneumo- nie gehört hierzulande zu den häufigsten Infektionskrankheiten. Mit dem Alter steigen Inzidenz und Letalität. Die häufigsten Erreger sind Pneumokokken.

\section{Diagnostik und Risikoabschätzung}

Für die Diagnosestellung gelten die in Tab. 1 beschriebenen Kriterien. Bei alten Menschen zeigt sich eine Pneumonie oft nur mit geringfügigem Husten und wenig Auswurf, einer erhöhten Atemfrequenz, Schwäche, Abgeschlagenheit, Gewichtsverlust oder einem Delir als einzigem initialem Symptom. Fieber kann ganz fehlen. Mit Schnelltests lassen sich vor Ort bzw. in der Praxis die Entzündungswerte C-reaktives Protein (Blue-

\section{Tab. 1 Diagnostik der Pneumonie}

\begin{tabular}{|c|c|}
\hline \multicolumn{2}{|c|}{$\begin{array}{l}\text { Neu aufgetretenes oder progredientes } \\
\text { Infiltrat im Röntgenbild }\end{array}$} \\
\hline $\begin{array}{l}\text { zusätzlich folgende } \\
\text { klinische Zeichen }\end{array}$ & $\begin{array}{l}\text { und mindestens } 2 \text { der } \\
\text { folgenden Kriterien }\end{array}$ \\
\hline 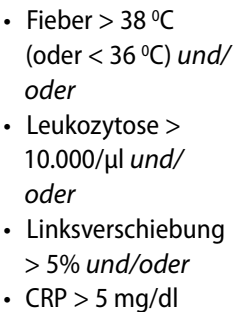 & $\begin{array}{l}\text { - produktiver Husten } \\
\text { - purulenter Auswurf } \\
\text { - Dyspnoe/Tachypnoe } \\
\text { - Schüttelfrost } \\
\text { - atemabhängige } \\
\text { Thoraxschmerzen } \\
\text { - feinblasige Rassel- } \\
\text { geräusche }\end{array}$ \\
\hline
\end{tabular}

Cross CrP-Test) oder Procalcitonin (PCTQ-B.R.A.H.M.S.) bestimmen.

Zur Entscheidungsfindung, ob eine Einweisung in die Klinik nötig ist, bietet sich die Risikoanalyse nach CRB-65 an (Tab. 2). Bei zwei oder mehr Punkten ist eine stationäre Behandlung zu empfehlen.

\section{Therapie}

Pneumokokken sind gegenüber einer Antibiotikatherapie äußerst empfindlich: Bereits 24 Stunden nach Therapiebeginn besteht keine Infektiosität mehr.

Behandelt wird mit einem $\beta$-LaktamAntibiotikum in Kombination mit einem Makrolid. Neben Amoxicillin + Clavulansäure können auch Ampicillin + Sulbactam, Cefuroxim oder Fluorchinolone bei Allergien eingesetzt werden. Die Therapiedauer beträgt 5-10 Tage (bzw. 3-5 Tage nach Entfieberung und Erreichen stabiler Vitalparameter).

\section{Besonderheiten bei Heimbewohnern}

Bei Pflegeheimbewohnern besteht die Gefahr, dass sich mit einer Klinikaufnahme der Gesundheitszustand verschlechtert. Vor allem kognitiv eingeschränkte Patienten reagieren auf die Milieuveränderung sehr empfindlich. Um die Versorgung im Heim zu ermöglichen, müssen allerdings einige Voraussetzungen wie geschultes Pflegepersonal, die schnelle und zuverläs-

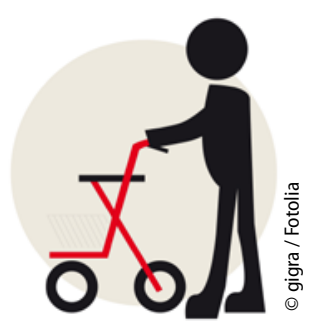

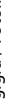
. 